\title{
Influence of Vanadium and Boron Additions on the Microstructure, Fracture Toughness, and Abrasion Resistance of Martensite-Carbide Composite Cast Steel
}

\author{
Waleed Elghazaly, ${ }^{1}$ R. Rashad, ${ }^{2}$ Sayed Elmohr, ${ }^{3}$ and Saied Elghazaly ${ }^{1}$ \\ ${ }^{1}$ Steel Technology Lab, Central Metallurgical R\&D Institute, Cairo, Egypt \\ ${ }^{2}$ Mechanical Design, Production Engineering, Cairo University, Cairo, Egypt \\ ${ }^{3}$ Siegwart Co., Cairo, Egypt \\ Correspondence should be addressed to Saied Elghazaly; saiedelghazaly@yahoo.com
}

Received 26 April 2016; Revised 6 July 2016; Accepted 22 August 2016

Academic Editor: Patrice Berthod

Copyright (C) 2016 Waleed Elghazaly et al. This is an open access article distributed under the Creative Commons Attribution License, which permits unrestricted use, distribution, and reproduction in any medium, provided the original work is properly cited.

High chromium cast steel alloys are being used extensively in many industrial services where dry or wet abrasion resistance is required. Such steel castings are demanded for cement, stoneware pipes, and earth moving industries. In this research, five steel heats were prepared in $100 \mathrm{~kg}$ and one-ton medium frequency induction furnaces and then sand cast in both Y-block and final impact arm spare parts, respectively. Vanadium $(0.5-2.5 \%)$ and boron $(120-150 \mathrm{ppm})$ were added to the $18 \mathrm{Cr}-1.9 \mathrm{C}-0.5 \mathrm{Mo}$ steel heats to examine their effects on the steel microstructure, mechanical properties especially impact, fracture toughness and abrasion resistance. Changes in the phase transformation after heat treatment were examined using inverted, SEM-EDX microscopy; however, the abrasion resistance was measured in dry basis using the real tonnage of crushed and milled stoneware clay to less than $0.1 \mathrm{~mm}$ size distribution.

\section{Introduction}

Steel designers and researchers seek always to develop alloys that can give a balanced strength and toughness, for example, high wear resistant together with high fracture toughness [1, 2]. One of the well-known abrasion resistant ferrous materials is high chromium white cast iron $(20-30 \% \mathrm{Cr}, 3.5-4 \% \mathrm{C}$, and $1-5 \% \mathrm{Mo}$ ) which has excellent wear resistance, but unfortunately poor toughness or ductility due to the bigger matrix grain size and the massive brittle leduburitic eutectic carbide precipitations that occur in a continuous, three-dimensional network surrounding the dendrite matrix grains [3-5]. The fracture toughness of the cast iron shows minimal values (10$25 \mathrm{Mpa} \cdot \mathrm{m}^{1 / 2}$ ) as a result of brittle carbide precipitations [6]. Many researches were trying to increase the abrasion resistance of cast iron by alloying with wolfram, vanadium, or niobium but the product toughness was always deteriorated [79]. In this research and aiming to keep high wear resistance and more tough matrices, trials to design cast steel alloys with lower carbon content, well-distributed harder carbides, and a matrix of tempered martensite and some retained austenite were studied.

The idea of producing steel alloys with lower carbon content together with vanadium and boron additions can be a promising solution to increase the toughness and wear resistance of such alloys.

\section{Experimental Procedure}

In this investigation, five steel heats were prepared using coreless, medium frequency, induction furnace. The alloys under investigation are the products of melting and casting special tool steel scraps collected from used tools and dies ( DIN X210Cr12) scrap offered by Universal Engineering Group. Ferroalloys, low sulfur graphite, and clean steel scrap were used to adjust the final compositions designed in this investigation. Ferroalloys used comprised low-carbon ferrochromium $(0.1 \% \mathrm{C}, 80 \% \mathrm{Cr})$, ferrovanadium $(80 \% \mathrm{~V})$, 


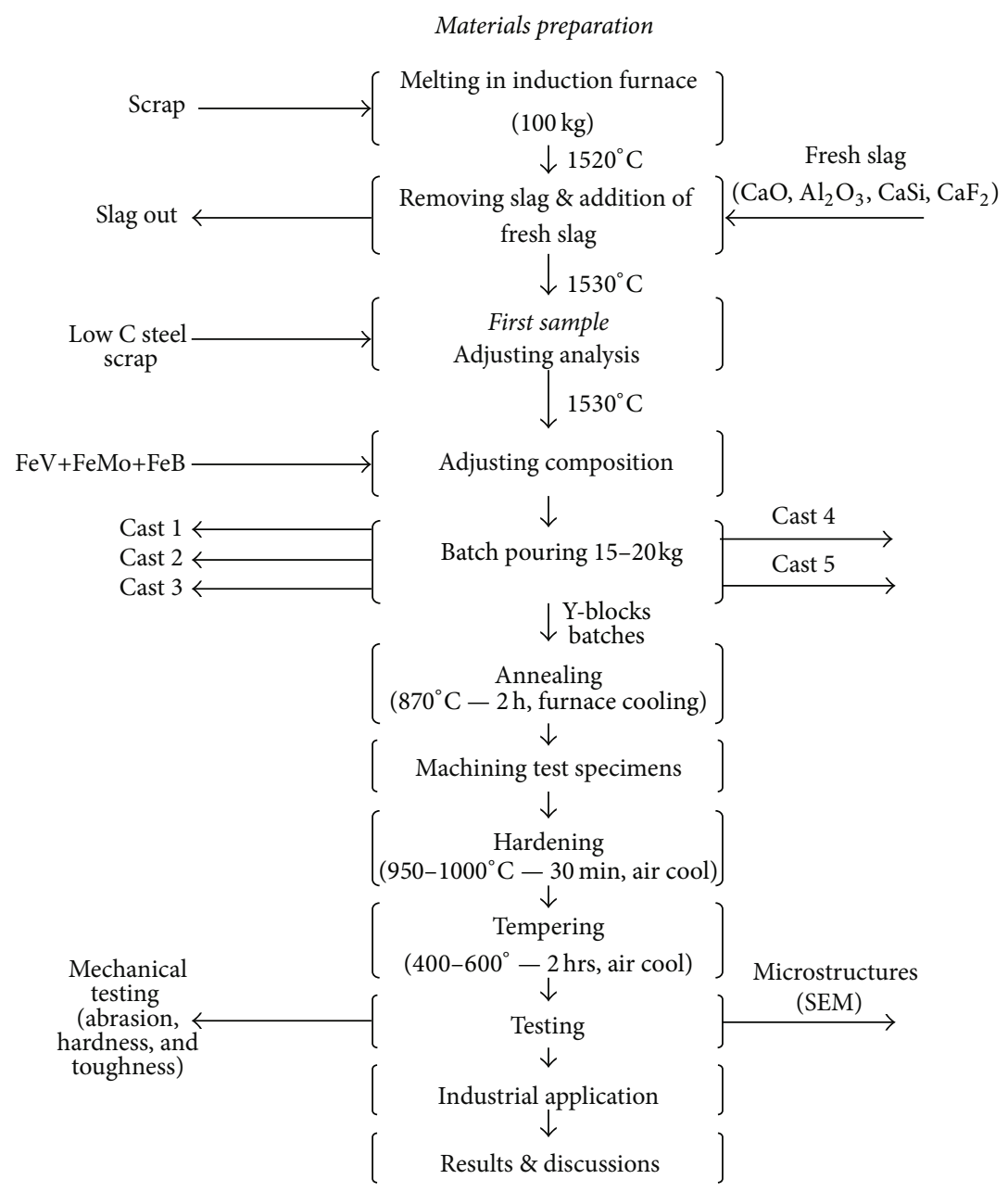

FIGURE 1: Overall plan of melting, casting, and testing of experimental alloys.

ferroboron (35\% B), ferromolybdenum ( $80 \% \mathrm{Mo})$, and pure aluminum $(99.9 \% \mathrm{Al})$. Fresh slag materials were used in composition of low melting calcium aluminates together with $\mathrm{Al}-\mathrm{CaSi}$ powder. The region of low melting $\mathrm{Ca}$-aluminates of compositions $12 \mathrm{CaO} \cdot 7 \mathrm{Al}_{2} \mathrm{O}_{3}$ in binary $\mathrm{CaO}-\mathrm{Al}_{2} \mathrm{O}_{3}$ system, which is liquid at about $1415^{\circ} \mathrm{C}$, was chosen to form the slag constituents. Thermite mixture of aluminum and iron oxide powders was also added to the top of slag under the furnace cover to give exothermic heat to keep continuous metal/slag active mass transfer. The lining was chosen to be high alumina one not only to withstand melting temperature but also to not interact chemically with both slag and the alloy melt. The furnace cover was also rammed from high alumina bonded powder, to preserve the heat of the top slag to ensure good metal protection and better mass transfer through metal/slag interface. After complete melting $\left(1520^{\circ} \mathrm{C}\right)$, first oxidizing slag (negligible) was removed and the other 3$5 \mathrm{~kg}$ fresh slag materials were added to refine melt from any impurities. Ferroalloys were then added to correct the required final analysis of every alloy. The overall plan of work is projected as shown in Figure 1, where addition of correcting ferroalloys, carbon and aluminum, was performed to adjust the final alloy compositions. The final casting temperature was adjusted at $1530^{\circ} \mathrm{C}$ using dipping thermocouple or optical pyrometer. Every melt was tapped and cast in designed cavity and experimental Y-block as well, preheated $\left(250^{\circ} \mathrm{C}\right)$ sand moulds sprayed with refractory $\mathrm{ZrO}_{2}$ according to DIN EN 1536 type 3. Figure 2 represents a schematic drawing of the experimental cast Y-block and casting pattern. Before casting of the first heat, addition of scrap and/or ferroalloys was performed to adjust the composition of the final alloy. The cover lid of the furnace was always kept closed, to ensure no further oxidation of the melt by atmospheric air; moreover, inert atmosphere under the furnace lid was achieved using Argon lancing. This is to ensure effective removal of shrinkage cavity from the main cast blocks.

\section{Results and Discussions}

The final chemical analysis of the five experimental steel patches is shown in Table 1.

In this investigation, the melting procedure was designed to get final steel casts different in vanadium and boron content, but with nearly the same basic composition. It is evident that the content of dissolved aluminum in all steel ranged 
TABLE 1: Chemical analysis of the steel patches.

\begin{tabular}{lccccccr}
\hline Material & $\mathrm{C}$ & $\mathrm{Mn}$ & $\mathrm{Si}$ & $\mathrm{Cr}$ & $\mathrm{Mo}$ & $\mathrm{V}$ & $\mathrm{B}$ \\
\hline GS-1 & 1.98 & 0.63 & 0.80 & 18.56 & 0.57 & - & - \\
GS-2 & 1.99 & 0.73 & 0.79 & 18.91 & 0.61 & 0.59 & - \\
GS-3 & 1.98 & 0.76 & 0.83 & 18.56 & 0.59 & 1.51 & - \\
GS-4 & 1.94 & 0.69 & 0.76 & 18.32 & 0.63 & 1.56 & 0.027 \\
GS-5 & 1.97 & 0.80 & 0.81 & 18.69 & 0.59 & 2.56 & 0.035 \\
\hline
\end{tabular}

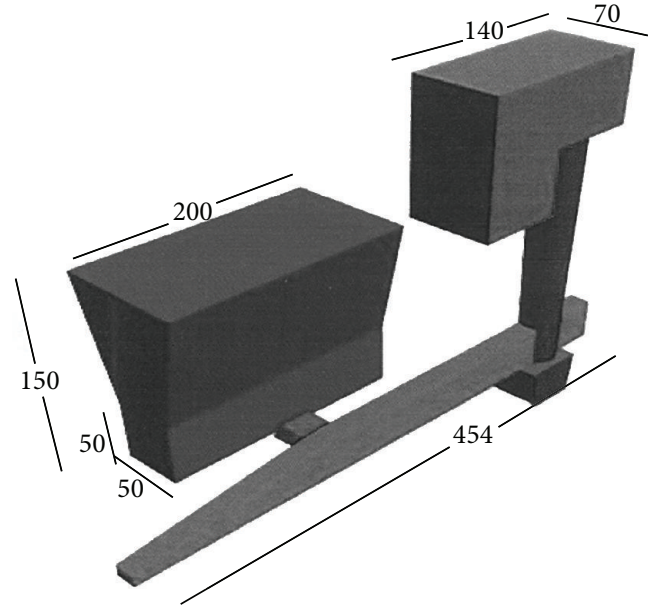

FIGURE 2: Geometry of casting Y-block mould.

from 0.027 to 0.039 as an indication that the experimental melts were killed to have 3-5 ppm maximum dissolved oxygen; this ensures minimized casting cavities.

\subsection{Microstructure Investigation}

3.1.1. As-Cast Conditions. Vanadium, chromium, molybdenum, and boron are reported to affect the transformation behavior of austenite [10]. The as-cast microstructures of hypereutectoid $18 \%$ Cr-1.9\% C-0.5\% Mo experimental GS.15 alloys consist of mainly metastable dendrites of primary austenite (dark phase) + mixed primary and eutectic carbides (white phase) and martensite as shown in Figures 3, 4, 5(a), and 5(b). Emission-diffraction X-ray (EDX) analyses revealed that the primary carbides consists mainly of chromium carbides of type $\mathrm{Cr}_{7} \mathrm{C}_{3}$ colonies which have a hexagonal structure with lattice parameters $a=13.982 \AA$ and $c=4.507 \AA$; this type of carbide has many structural defaults and forms during solidification as austenite rejects some of its carbon. The morphology of such complex carbides depends to a great extent on the solidification and casting technology; however, rod or blade (multiple rods) and radiating shaped carbides of type $\mathrm{Cr}_{7} \mathrm{C}_{3}$ are normally formed during and after solidification as shown in Figures 6(a) and 6(b). The austenite phase remains in metastable condition at room temperature as in alloy GS-1 due to suppression of martensite start temperature; however, by alloying with vanadium and boron more carbides are formed by reacting with adjacent carbon, this creates in turn areas of depleted carbon that transforms in turn to martensite during further cooling depending on the content of vanadium added.

The grain refinement of dendrites as well as type and morphology of carbides changed to some extent on adding vanadium as in alloys GS-2 and GS-3 having 0.59\% and $1.51 \%$ vanadium, respectively, where vanadium-rich carbide is identified by EDX analysis as $\mathrm{V}_{6} \mathrm{C}_{5}$ or complex Fe-Cr-V depending on the content of vanadium in the alloy.

During solidification, austenite dendrite forms first and rejects some of its saturation carbon which reacts in sequence with vanadium, chromium, and iron to form primary single or complex carbide depending on their affinity, diffusivity, temperature, and concentration. The carbide phases nucleate side by side with/within the austenite dendrites forming rods or blades. In alloy GS-3 where vanadium content is about $1.5 \%$, the volume fraction of primary austenite (as detected by $\mathrm{X}$-ray diffraction) is decreased to some extent and a massive precipitation of $\mathrm{V}_{6} \mathrm{C}_{5}$ and $\mathrm{Cr}_{7} \mathrm{C}_{3}$ (as detected by EDX analyzer) resulting in narrowing dendrite arm spacing; this can be noticed by comparing the microstructure of GS-3 with GS-1 and GS-2.

The as-cast microstructures of alloy GS-5 having 2.5\% vanadium together with 0.012 and $0.015 \%$ boron showed massive precipitation of both primary and secondary carbides hindering grain growth of dendrite arms. Volume fraction of austenite and carbides for the cast alloys, as detected using $\mathrm{X}$-ray diffraction and EDX analyzer, is shown in Table 2.

3.1.2. Heat Treated Metal Matrix. The experimental heats GS1 to GS-5 were heat treated using the published data on cooling curves for near compositions [11] where the start of transformation during cooling is retarded for about $3-5 \mathrm{~h}$ depending on the contents of carbon and alloying elements of the steel. For the overall heat treatment cycle used in this research, the annealing temperature, suitable to machine the test samples, was chosen at $870^{\circ} \mathrm{C}$ for two hours, while hardening temperatures were chosen in the range $950-1000^{\circ} \mathrm{C}$ for 30 minutes, quenching in still air or oil and then tempering in the range $400-600^{\circ} \mathrm{C}$ for $2 \mathrm{~h}$. The overall microstructure of the alloys consists of tempered martensite, metastable or retained austenite, complex primary carbides, and secondary carbides as shown in Figures 7 and 8(a)-8(d). Alloying of the steels with variable amounts of vanadium and boron retards the grain growth of primary carbides as in (a) and (d) microstructures as compared with alloy GS-1 having (c) microstructure.

The presence of more alloying elements of vanadium and boron as in alloy GS-5 leads to dispersive carbide colonies 
TABLE 2: Volume fraction of austenite and carbides in cast alloys.

\begin{tabular}{lccccc}
\hline Heat & Condition & Vol.\% & Vol.\% & Vol.\% & Dendrite arm spacing, $\mu \mathrm{m}$ \\
\hline GS-1 & As cast & 42.3 & $\mathrm{M}_{7} \mathrm{C}_{3}$ & $\mathrm{~V}_{6} \mathrm{C}_{5}+\mathrm{BC}$ & 18.4 \\
GS-2 & As cast & 37.9 & 28.7 & 8.5 & 15.1 \\
GS-3 & As cast & 30.7 & 21.2 & 10.4 & 14.9 \\
GS-4 & As cast & 30.3 & 19.5 & 11.9 & 10.6 \\
GS-5 & As cast & 27.8 & 21.6 & 17.5 & 8.3 \\
\hline
\end{tabular}

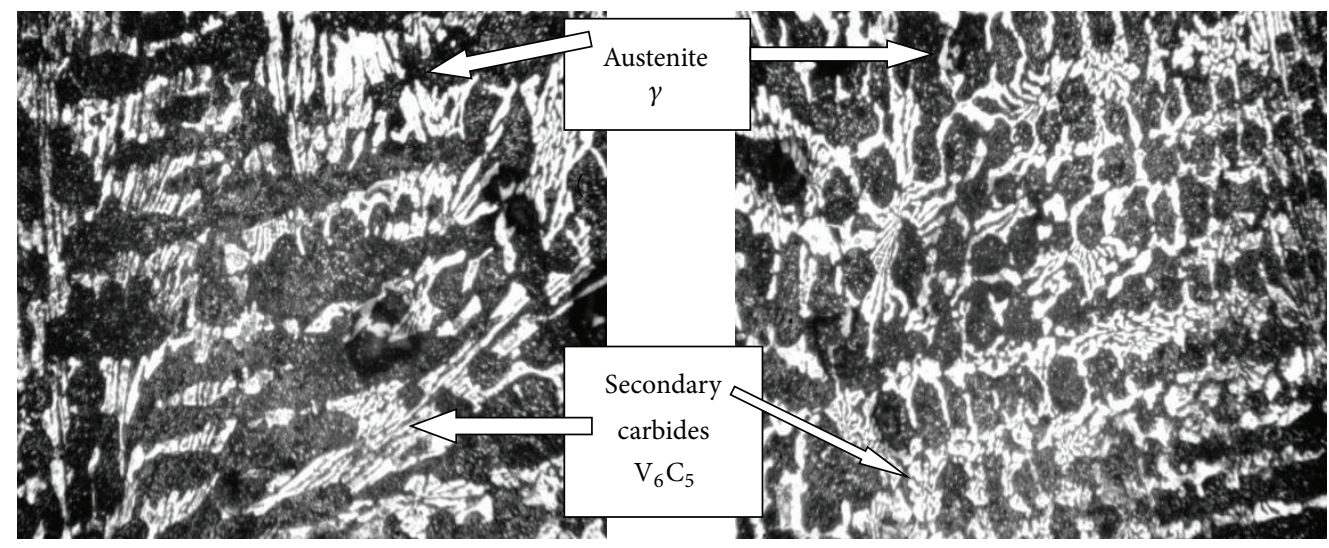

(a) GS-1

(b) GS-2, $0.5 \% \mathrm{~V}, \times 100$

Figure 3: As-cast microstructure of GS-1 and GS-2 experimental steel.

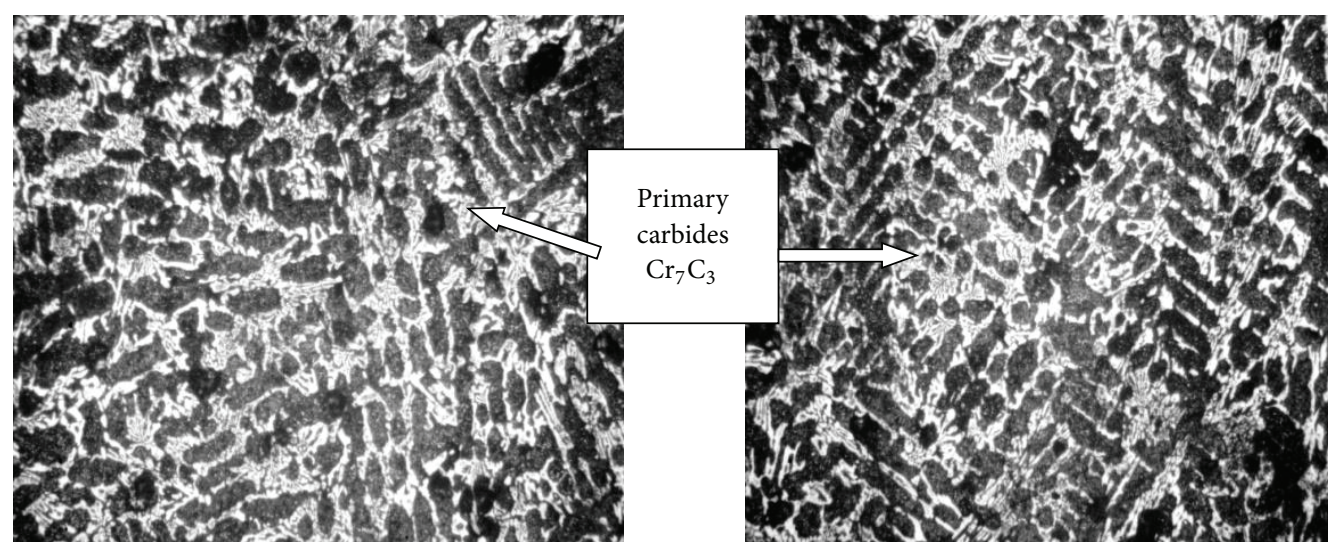

(a) GS-3, $1.5 \% \mathrm{~V}$ (b) GS-4, $1.5 \% \mathrm{~V}+0.012 \% \mathrm{~B}, \times 100$

FIgURE 4: As-cast microstructure of GS-3 and GS-4 experimental steel.

and the absence of dendrite structure and ensures more fine distribution of carbides as in (b) microstructure. Xray diffraction techniques together with emission-diffraction EDX scanning analyses were used to determine the types and compositions of phases and carbides transformed after heat treatment; however, it was not precise to determine the volume fractions of phases due to the interference of dominated martensite phase. More measurements for the heat treated microstructures for such steels especially GS3, GS-4, and GS-5 need further investigation in the coming future researches.

\subsubsection{Mechanical Properties}

(1) Hardness. The effect of obtained microstructures on the hardness values of GS alloys is summarized as in Figure 9; the bulk or microhardness of the GS improved indeed by increasing the vanadium content in the as-cast, quenched, and quenched tempered as compared with $25 \%$ Cr cast iron. This can be attributed to the increased volume fraction of the primary carbides $\mathrm{Cr}_{7} \mathrm{C}_{3}$ and the secondary $\mathrm{V}_{6} \mathrm{C}_{5}$ carbides; however, $\mathrm{BC}$ intermetallic precipitates harden the matrix as well. After quenching and tempering at $400-600^{\circ} \mathrm{C}$, 


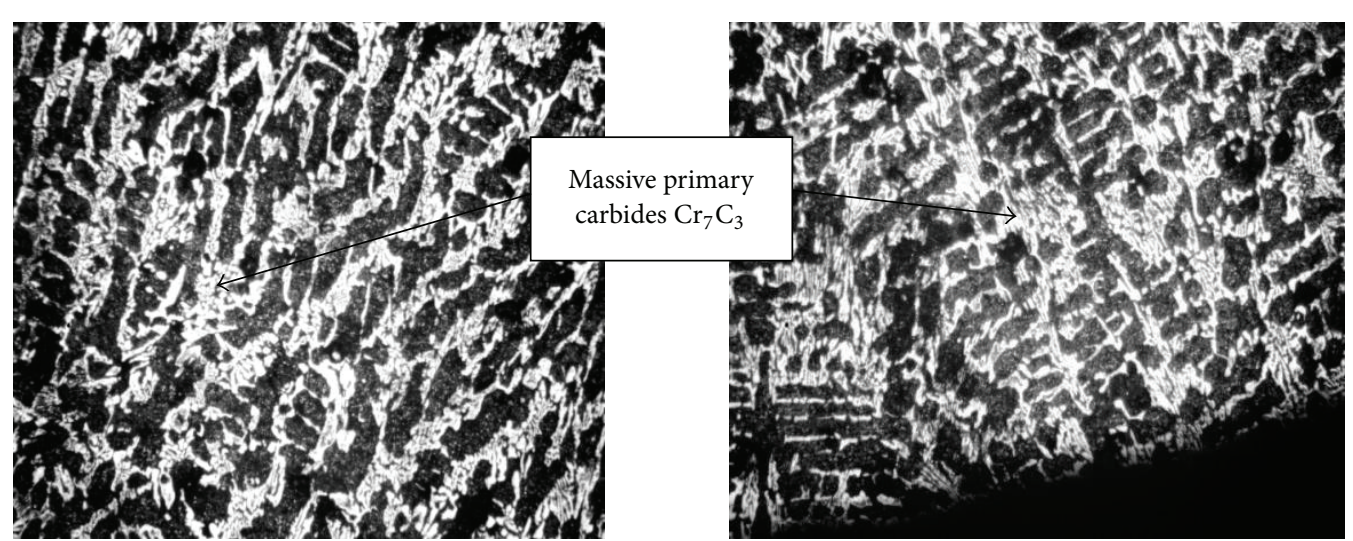

(a) GS-5, $2.5 \% \mathrm{~V}+0.015 \% \mathrm{~B}$ (b) GS-5 near the chill edge, $\times 100$

FIgURe 5: As-cast microstructure of GS-5 (2.5 V + 0.015 B) experimental steel.

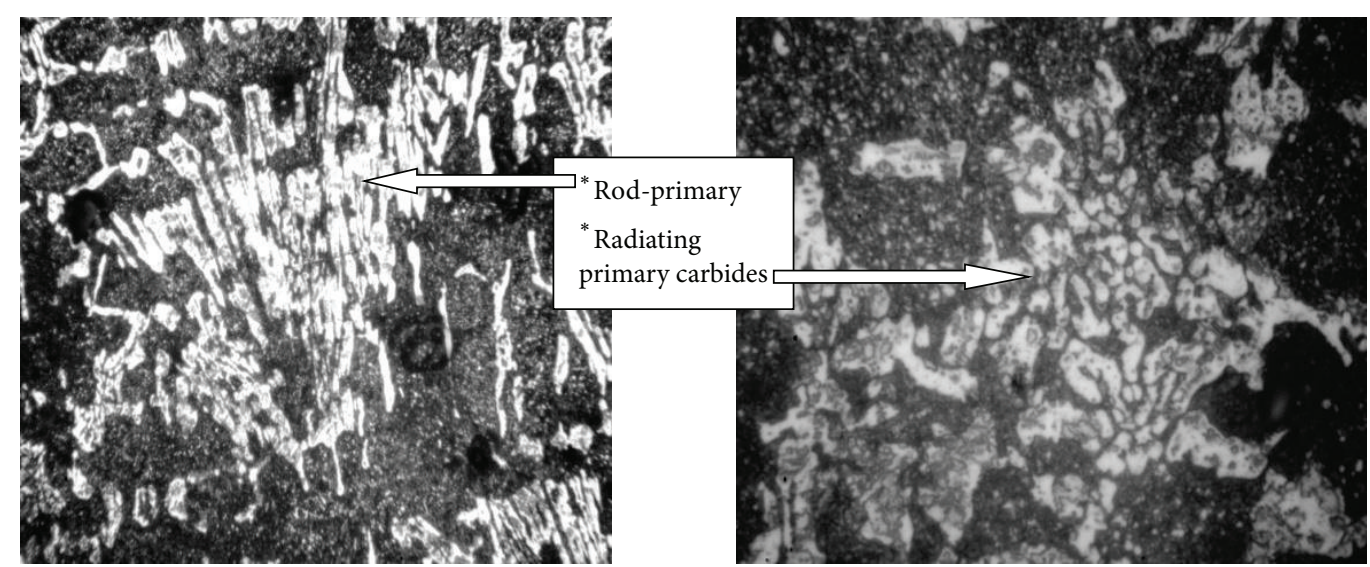

(a)

(b) $\times 600$

FIgURE 6: Morphology of rod-like primary carbides and radiating and secondary carbides.
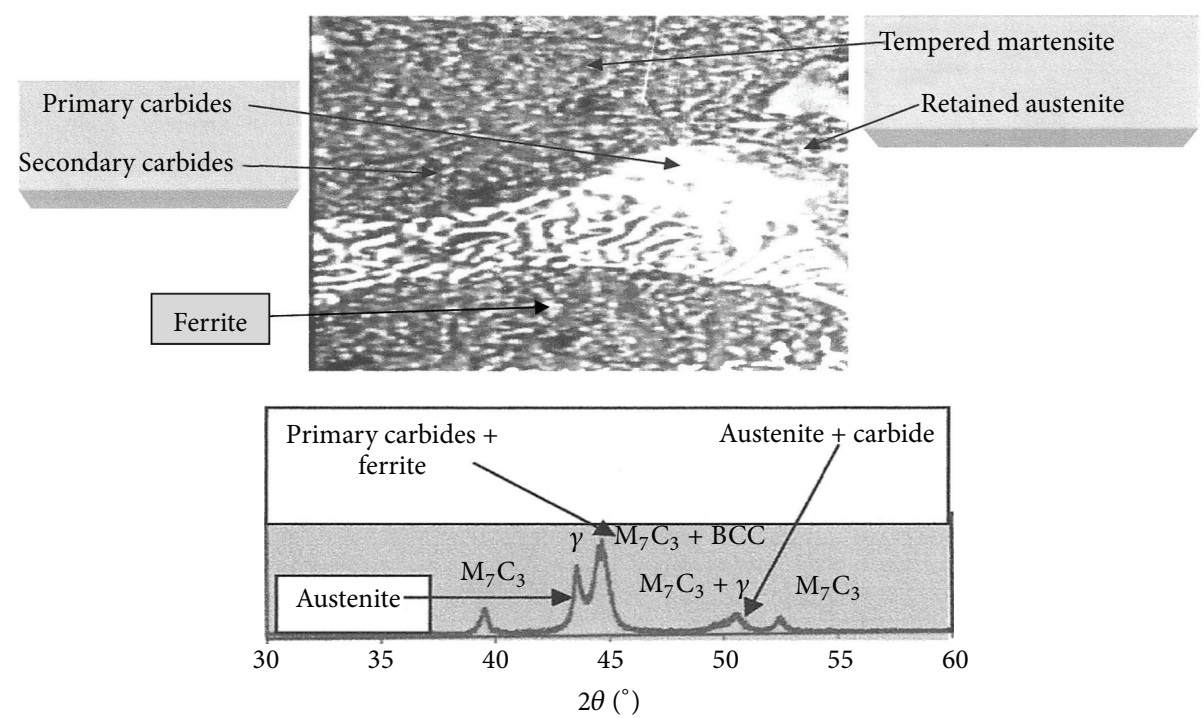

FIGURE 7: Typical microstructure of experimental steel after heat treatment, as revealed by X-ray diffraction [hardening $980^{\circ} \mathrm{C}-\mathrm{AC}$, tempering $\left.600^{\circ} \mathrm{C}, 2 \mathrm{~h}\right]$. 


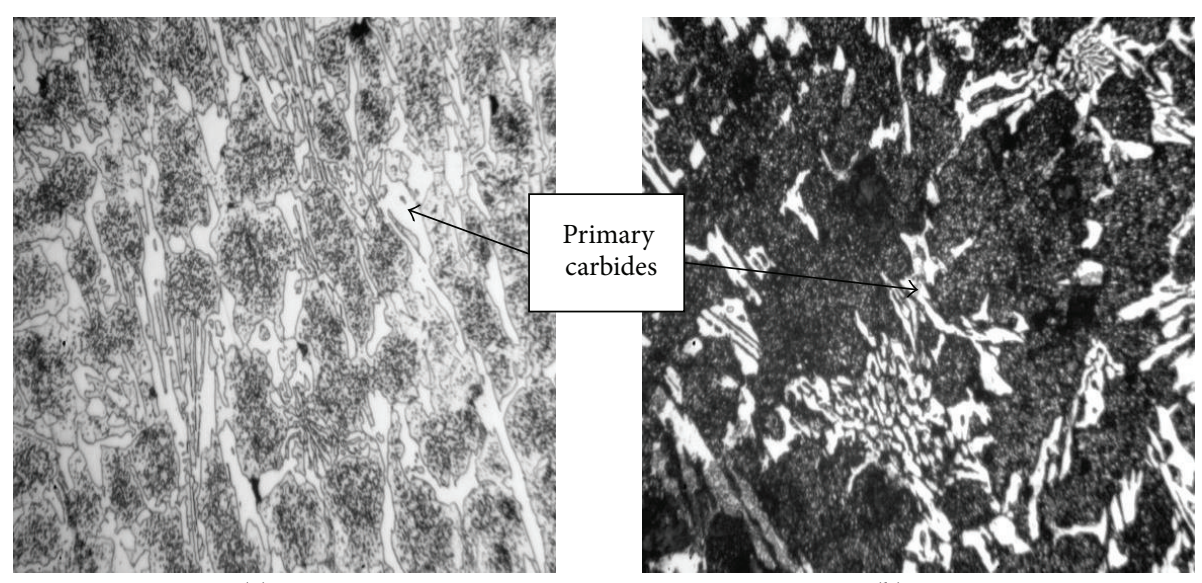

(a) $\times 400$

(b) $\times 600$

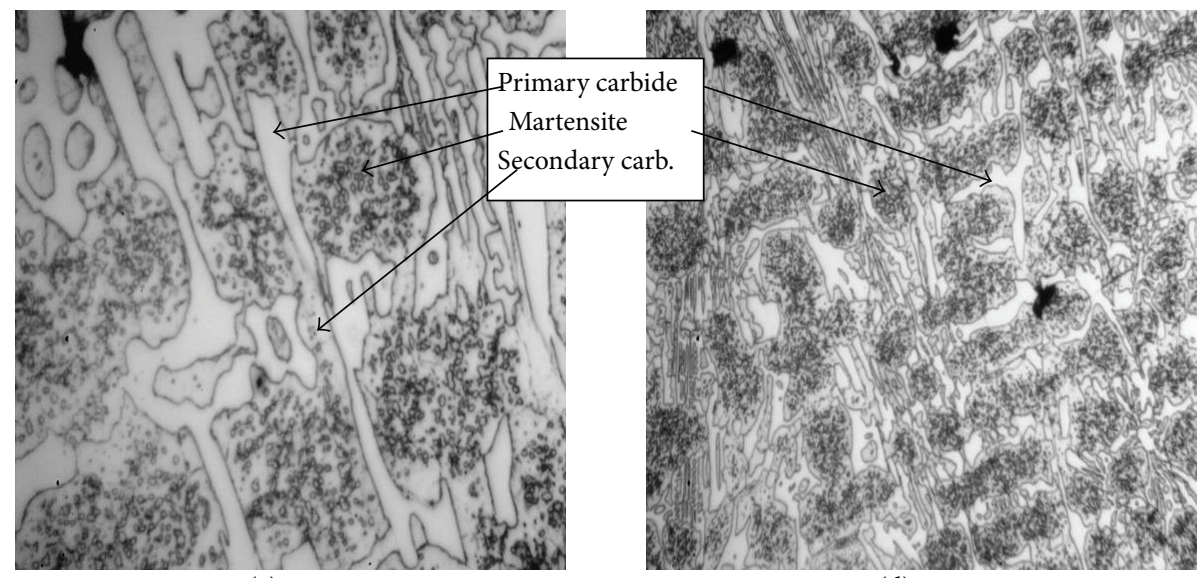

(c) $\times 400$

(d) $\times 400$

FIGURE 8: (a-b) Morphology of primary carbides in heat treated microstructures of experimental steel GS-4 and steel GS-5. (c-d) Appearance of quenched and tempered microstructures.

the precipitation of carbides and the transformation of primary and secondary austenite to martensite improve the hardness of GS alloys.

3.2. Influence of $V$ and $B$ on Fracture Toughness. Due to nonhomogenous cast structures and their high volume fraction of brittle carbides, the alloys under investigation showed low ductility values $\left(5-15 \mathrm{~J} / \mathrm{cm}^{2}\right)$; for those reasons the Charpy $\mathrm{V}$ or $\mathrm{U}$ notch cannot give real measurements. Therefore and from fracture mechanics point of view, the most straightforward parameter to characterize fracture toughness is the critical stress intensity factor $(K)$ or dynamic fracture parameter $\left(K_{\text {id }}\right)$. Fracture toughness $K_{c}(\mathrm{~Pa} \cdot \sqrt{\mathrm{m}})$ measurements were made on primary carbide matrix at room temperature by the indentation factor method [12] which can be calculated from the width of crack induced on applying the Vickers Pyramid hardness test as follows (Figure 12):

$$
K_{c}=\frac{\alpha \sqrt{E P}(d / 2)}{\sqrt[3]{a 2}},
$$

where, for those cast alloys, there is total crack edge distance (m), E Young's modulus (310-350 GPa), P load (about $30 \mathrm{~kg}$ ), and a half length of crack $(m), d$ is the diagonal length of indentation, and $\alpha$ is calibration factor (about 0.025 depending on the surface finish).

A comparison of calculated fracture toughness of produced alloys GS1-5 in as-cast, quenched tempered conditions and $25 \%$ Cr cast iron, using bulk Vickers hardness testing machine, is shown in Figure 10. It is evident that alloys having vanadium content higher than $1.5 \%$ suffer from deteriorated fracture toughness in as-cast or even in tempered conditions; however, the toughness for all alloys in as-cast or heat treated conditions is higher than that for chromium cast iron. This can be attributed to the grain refinement of the alloy matrix due to the pinning action caused by secondary carbides precipitated and solid solution hardening caused by vanadium and boron and the lower carbon contents as well.

3.3. Industrial Abrasion Monitoring. Impact arms and grinding segments were produced from these experimental alloys as spare parts for Hazemag and Eirich stoneware (lean or fired) crushing and milling systems. The results were collected as actual product of crushed and milled powders ( $0.1 \mathrm{~mm}$ max). It is evident from Figure 11 that the mechanism of reinforcing the produced alloys with vanadium and boron 


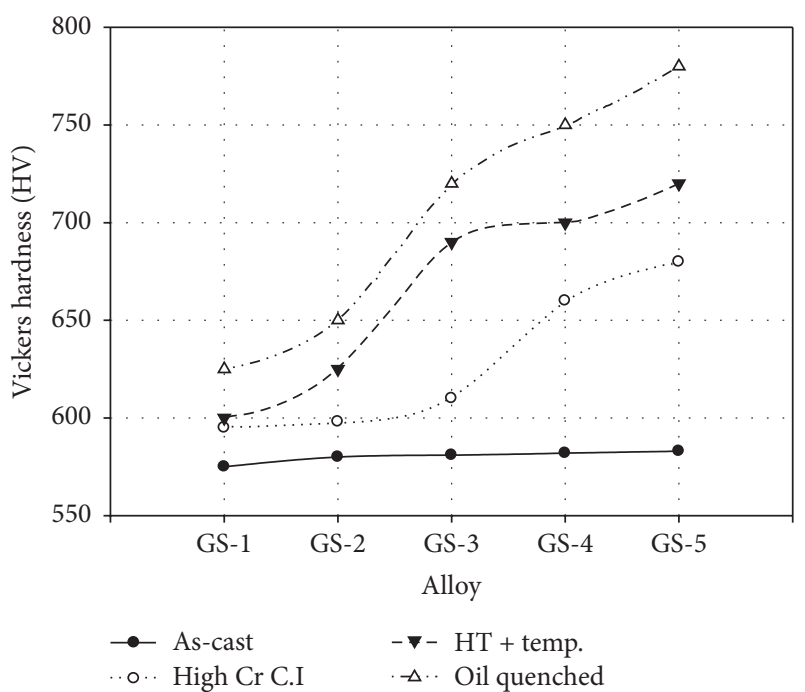

FIgURE 9: Hardness values of GS alloys as compared with 25\% Cr cast iron.

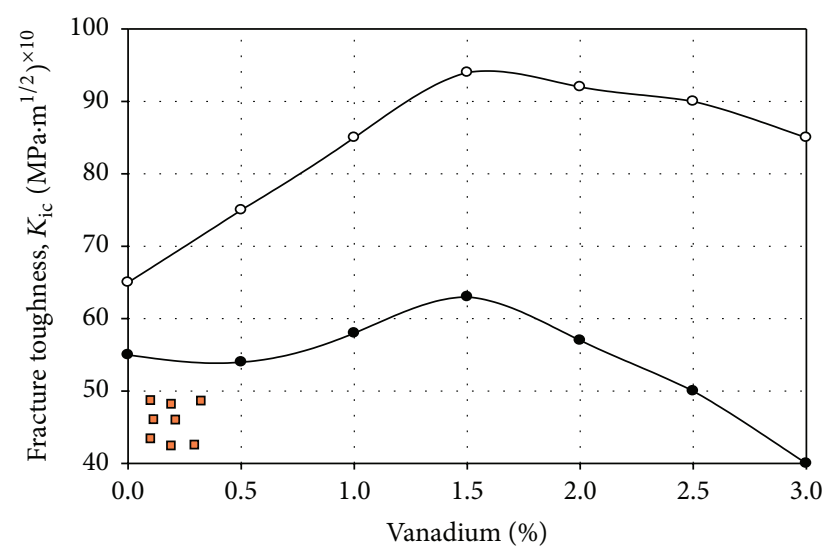

- As-cast

○ $\mathrm{GS},(\mathrm{Q}+\mathrm{T})$

口 High Cr C.I

FIGURE 10: Influence of vanadium on fracture toughness coefficient as measured for GS alloys in comparison with $25 \% \mathrm{Cr}$ cast iron.

carbides at that lower carbon level resulted in much higher wear resistance than that for high chromium cast iron.

\section{Conclusions}

From the above measurements and discussions, the following conclusions can be put as follows:

(1) The microstructures of the experimental steel GS-1 to GS-5 in both as-cast and heat treated conditions are more fine and homogeneous if compared with those for white chromium cast iron; this is due to the lower carbon content and the effects of adding vanadium and boron. This leads to harder matrices than those for cast iron.

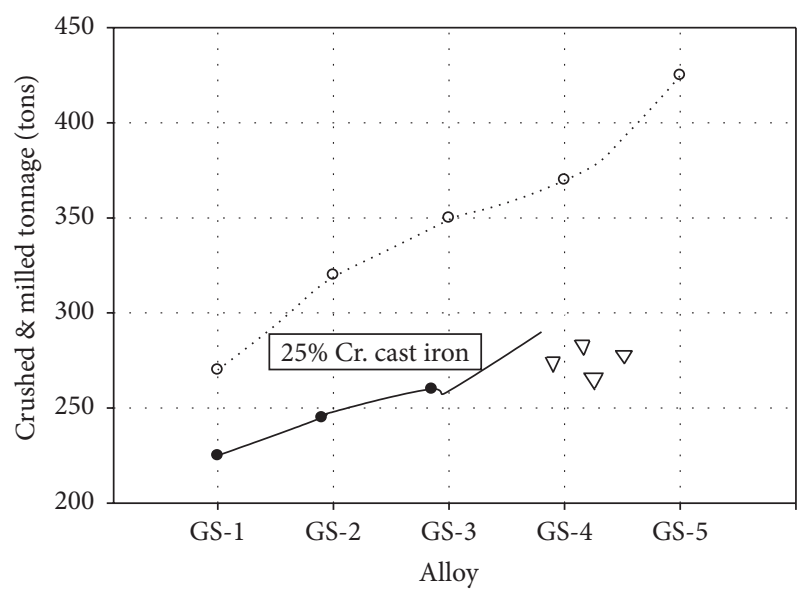

- $\mathrm{GS},(\mathrm{Q}+\mathrm{T})$

- Mn - Steel

$\nabla \mathrm{Mn}-$ steel $+\mathrm{Cr}$

FIGURE 11: Industrial performance of GS alloys compared with Mnmodified steel and $\mathrm{Cr}$ cast iron.

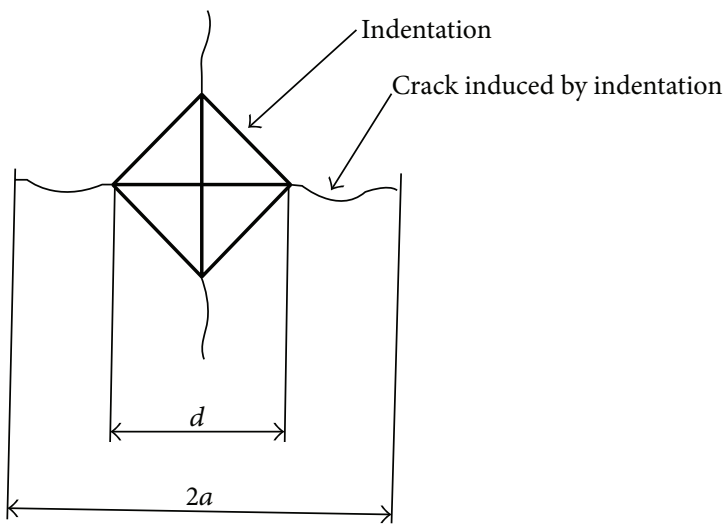

Figure 12

(2) The fracture toughness of the experimental steels is higher than that for cast iron due to refinement of the overall matrices and the well distributed primary and secondary carbides; this leads to high abrasion resistance and higher productivity.

(3) The wear resistance of the experimental quenched and tempered steel is 1.5 times higher than that for $25 \%$ Cr white cast iron.

\section{Competing Interests}

The authors declare that they have no competing interests.

\section{References}

[1] A. Kootsookos and D. Gates, "Development of a white cast iron," Cast Metals, vol. 4, no. 7, pp. 239-247, 1995.

[2] C. P. Tabrett and I. R. Sare, "Fracture toughness of highchromium white irons: influence of cast structure," Journal of Materials Science, vol. 35, no. 8, pp. 2069-2077, 2000. 
[3] M. Filipovic and Z. Kamberovic, "Correlation of microstructure with wear resistance and fracture toughness of the white cast iron," Met. Mater. Rev, vol. 41, pp. 59-82, 2013.

[4] Ö. N. Doğan, "Columnar to equiaxed transition in high $\mathrm{Cr}$ white iron castings," Scripta Materialia, vol. 35, no. 2, pp. 163$168,1996$.

[5] C. P. Tabrett, I. R. Sare, and M. R. Ghomashchi, "Microstructure-property relationships in high chromium white iron alloys," International Materials Reviews, vol. 41, no. 2, pp. 59-82, 1996.

[6] K.-H. Z. Gahr and D. V. Doane, "Optimizing fracture toughness and abrasion resistance in white cast irons," Metallurgical Transactions A, vol. 11, no. 4, pp. 613-620, 1980.

[7] A. Bedolla-Jacuinde, "Microstructure of vanadium-, niobiumand titanium-alloyed high-chromium white cast irons," International Journal of Cast Metals Research, vol. 13, no. 6, pp. 343-361, 2001.

[8] M. Fiset, K. Peev, and M. Radulovic, "The influence of niobium on fracture toughness and abrasion resistance in highchromium white cast irons," Journal of Materials Science Letters, vol. 12, no. 9, pp. 615-617, 1993.

[9] P. Dupin, "Influence of addition of silicon, molybdenum, vanadium and tungsten on the structural evolution of the as cast state of a high Cr-white cast iron," AFS Transactions, vol. 92, pp. 355360, 1984.

[10] G. Changqing and W. Caidong, "Effect of variable heat treatment modes on microstructure of Fe-Cr-B cast irons," Journal of Research and Development, vol. 5, no. 1, 2008.

[11] ASM International metals handbook V.1, 2000.

[12] K. Yamamoto, S. Inthidech, N. Sasaguri, and Y. Matsubara, "Influence of mo and $\mathrm{w}$ on high temperature hardness of M7C 3 carbide in high chromium white cast iron," Materials Transactions, vol. 55, no. 4, pp. 684-689, 2014. 

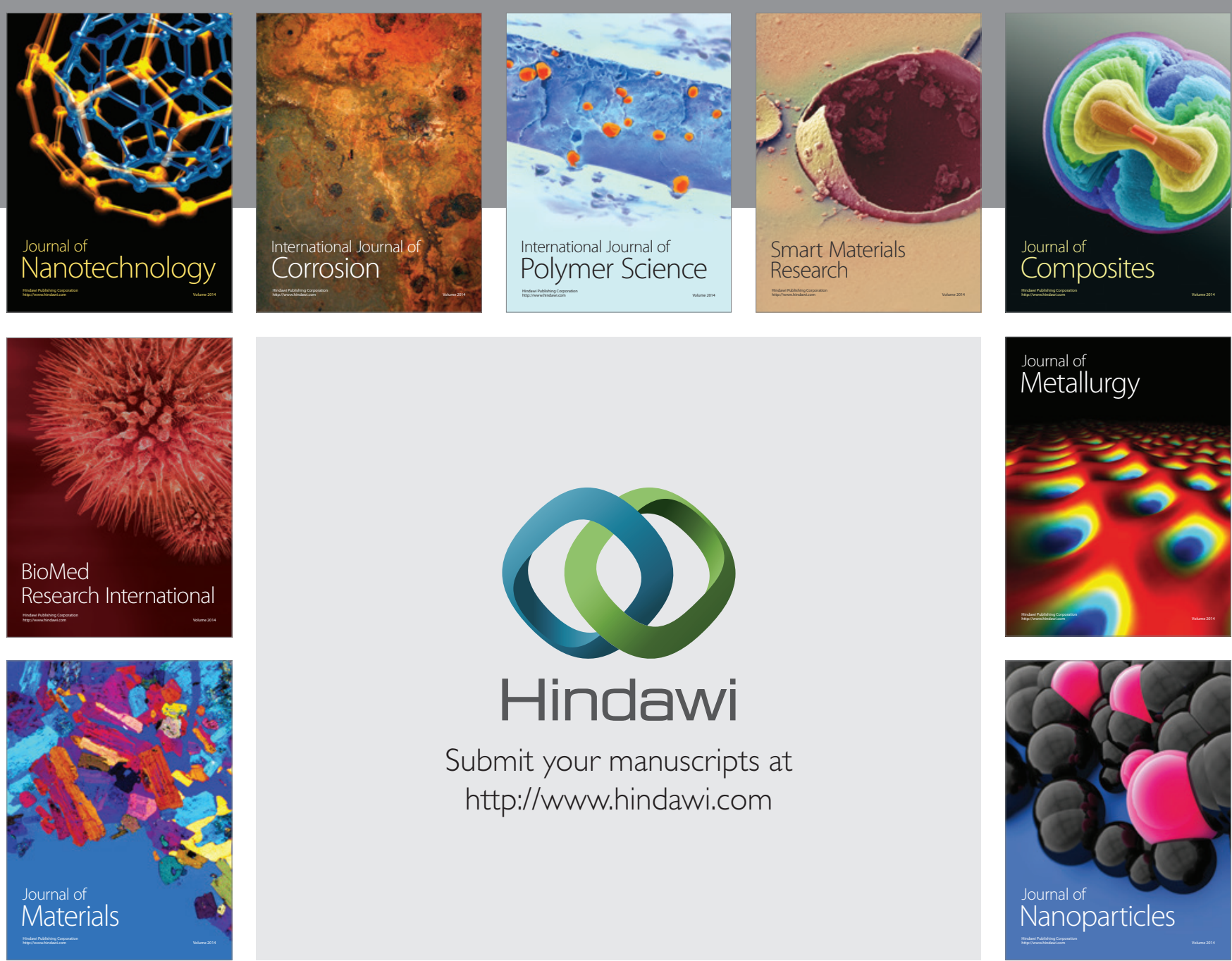

\section{Hindawi}

Submit your manuscripts at

http://www.hindawi.com

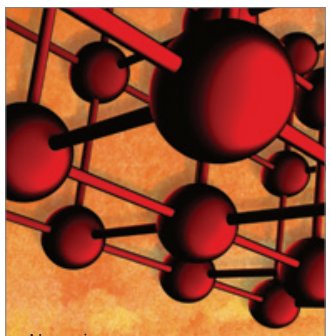

Materials Science and Engineering
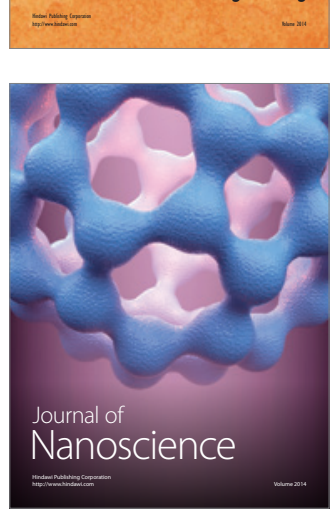
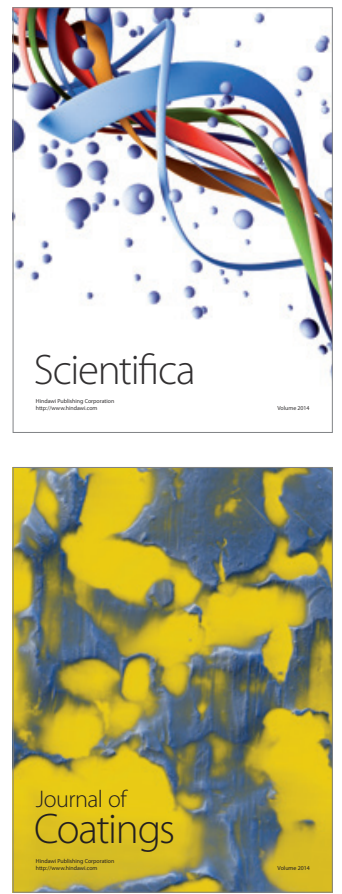
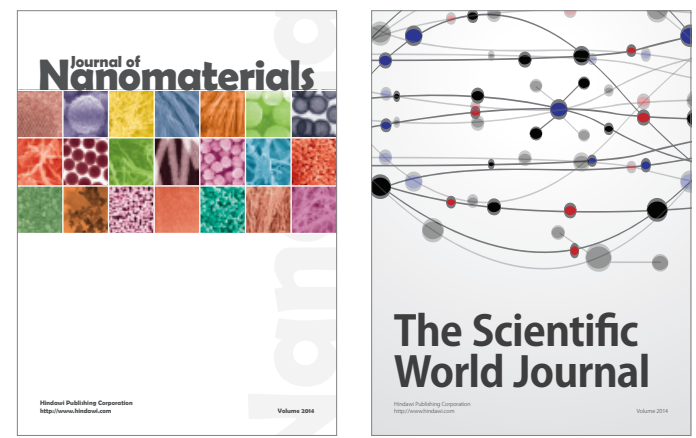

The Scientific World Journal
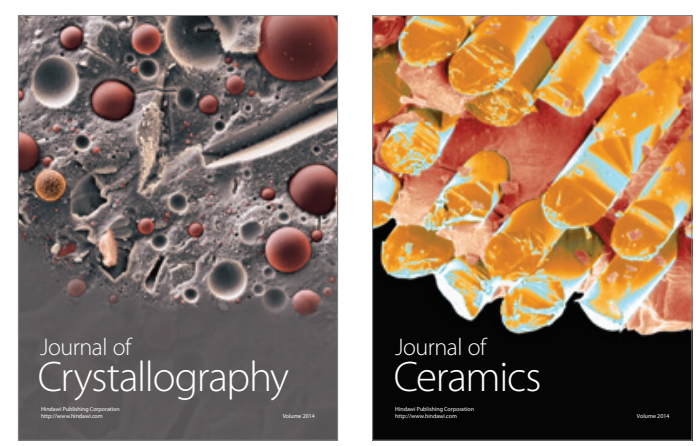
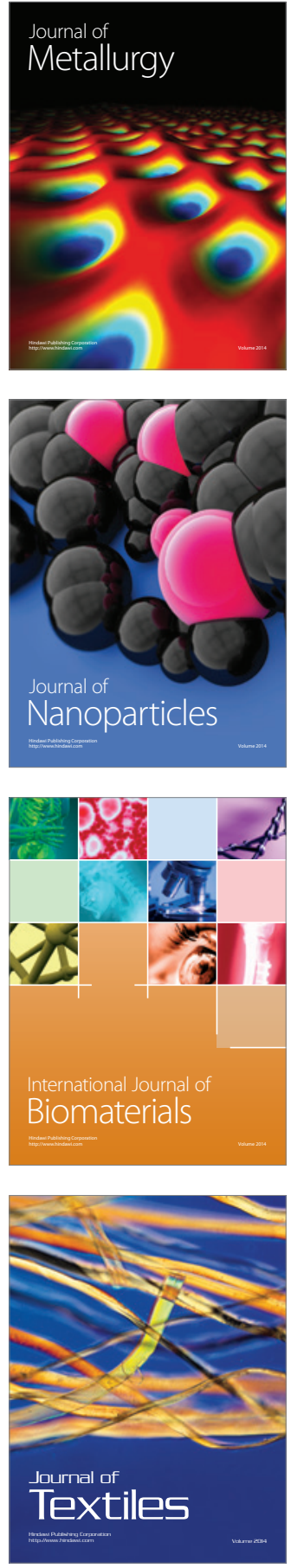